\title{
Tariff Setting In the Indian Power Sector-An Overview
}

\author{
J.N. Rai, Rishabh K. Gupta, Rahul Kapoor, Rajesh Garai \\ Electrical Engineering, Delhi Technological University, India
}

\begin{abstract}
Electricity tariff setting is a primary instrument of economic regulation. Tariff provides economic signals, which determine the volume and nature of the demand and supply of power. It is not surprising therefore that a considerable portion of the power sector reform effort is expended on rationalizing tariffs. Through this paper we aim to discuss the potential for alternative ways of charging for electricity and providing concessions to improve the affordability of essential electricity use, facilitate the equitable, efficient and full recovery of the cost of supplying electricity and provide clear information to consumers regarding the impact of their electricity use. Many of the existing tariff elements have been formulated over the years as a result of available technology. In reviewing the electricity tariff structures it is therefore important to consider some of the developments in technology particularly with respect to metering which may facilitate a greater variety in tariff structures now or in the future.
\end{abstract}

Keywords: tariff, availability based tariff (ABT), unscheduled interchange (UI), time-of-use tariff (ToU), critical peak pricing (CPP), real-time pricing (RTP), feed-in tariff (FiT), dynamic pricing, smart metering.

\section{Introduction}

Tariff means the schedule of rates or charges. Tariff, in case of electric supply, means the schedule or rates framed for supply of electrical energy to various classes of consumers. The main objective of the tariff is to distribute equitably the cost of supplying energy among the various classification of use. A tariff must recover cost of capital investment in generating, transmitting and distributing equipment, cost of operation, supplies and maintenance of equipment, cost of metering equipment, billing, collection costs and miscellaneous services \& should provide with a satisfactory return on the total capital investment. The principal factors involved in fixing of a tariff structure are expected to ensure a return is secured from each customer, the consumers are encouraged to make more extended use of electricity, the tariff should be simple $\&$ capable of explaining to the public, the consumers are charged according to what the energy costs, the consumers are encouraged to use electricity during off-peak hours, and penalized for high loads demanded at system peak by making a provision for higher demand charges $\&$ the customers are penalized for poor power factor.

\section{PRE-ABT SCENARIO}

Implementation of Availability Based Tariff for Central generating stations in India was recommended by M/s ECC of USA in 1994, under a study sponsored by the World Bank and ADB. A proposal for ABT, as a three-part tariff, was first mooted in the year 1994 in a report submitted by an International Consultant (ECC Report) to the Government of India. The introduction of Availability Based Tariff came about on 1st July, 2002 from the Western Region.

Prior problem in the Indian power sector was not only the shortage of power but also the difficulty in performing grid operations due to acute indiscipline shown by the generators as well as the beneficiaries. The generators could pump as much power in the grid as they could irrespective of the frequencies and still get acknowledged for the wastage of the valuable resource. The regional grid operators ironically had a horrifying time trying to get generators backed down to protect the turbines of the same generator causing the situation. On the other end the stated utilities could overdraw from the grid even during deficit and still escape creating a chaos and despair all around. There was this persistent problem of frequent power over-drawl from one of the State Beneficiaries, leading to grid instability. The transmission corridors were getting congested while bringing the excess amount of power from the remote locations to the load centers. There was a poor frequency regime followed i.e. low frequency during peak periods while during off-peak periods high frequency. The reason attributed to this is the existence of perverted incentives in the tariff regime at that time such as Recovery of capacity charges based on PLF and no differential payment for deviations from schedule.

\section{Availability Based Tariff}

Availability means the readiness of the generating station to deliver. The term availability in the present context could be defined as the MW capability of the generator for supplying to the grid after accounting for the planned and unplanned outages and deration due to non-availability of auxiliaries, fuel and water. Availability Based Tariff is concerned with the tariff structure for bulk power and is aimed at bringing about more responsibility 
and accountability in power generation and consumption through a scheme of incentives and disincentives. ABT stands for a rational tariff structure for power supply from generating stations on a contracted basis. The ABT is a tariff for transactions between the operator of the power plant or station and the beneficiary. ABT is a threepart tariff:

Capacity charges (fixed cost): full recovery at normative availability.

Energy charge (variable cost): up to scheduled energy, at normative tariff

Unscheduled Interchange: deviation from schedule, rate linked to frequency.

The fixed cost elements are interest on loan, return on equity, depreciation, O\&M expenses, insurance, taxes and interest on working capital. The payment of fixed cost to the generating company is linked to availability of the plant i.e. its capability to deliver MWs on a day-by-day basis. The total amount payable to the generating company over a year towards the fixed cost depends on the average availability (MW delivering capability) of the plant over the year. In case the average actually achieved over the year is higher than the specified norm for plant availability, the generating company gets a higher payment.

$$
\begin{aligned}
& R_{\text {capacity }}=\sum_{k=1}^{K} A_{k} C_{k} \\
& A_{k-\min } \leq A_{k} \leq A_{k-\max }: \frac{1}{K} \sum_{k=1}^{K} A_{k} \leq 100-O
\end{aligned}
$$

Equation (1) represents the annual earnings through capacity charges and incentive. Equation (1.1) sets the threshold limit on annual availability target by taking into account of mandatory planned maintenance. $A_{k-\max }$ also accounts for capacity degradation of units in different time intervals.

Where, $\mathrm{R}_{\text {capacity }}$ : Yearly revenue from capacity charges in rupees including incentive component, $\mathrm{K}$ : index of time blocks,

$\mathrm{A}_{\mathrm{k}}$ : Availability targets in $\%$ for $\mathrm{k}^{\text {th }}$ interval after station auxiliary power consumption- a decision variable,

$\mathrm{C}_{\mathrm{k}}$ : Capacity charges/incentive for $\mathrm{k}^{\text {th }}$ time block in Rupees per $\%$ of station availability (Determined from annual station fixed charges of CERC norm),

$A_{k-\max }$ : Maximum limit on availability target in $\%$ for the $\mathrm{k}^{\text {th }}$ time interval, after accounting for capacity degradation,

$\mathrm{A}_{\mathrm{k}-\min }$ : Minimum limit on availability target in $\%$ for the $\mathrm{k}^{\text {th }}$ time interval, and

O: Aggregate planned outage of generation units in $\%$ for a year.

Energy charge comprises of the variable cost (i.e., fuel cost) of the power plant for generating energy as per the given schedule for the day. It may specifically be noted that energy charge (at the specified plantspecific rate) is not based on actual generation and plant output, but on scheduled generation. In case there are deviations from the schedule (e.g., if a power plant delivers $600 \mathrm{MW}$ while it was scheduled to supply only 500 MW), the energy charge payment would still be for the scheduled generation (500 MW), and the excess generation $(100 \mathrm{MW})$ would get paid for at a rate dependent on the system conditions prevailing at the time.

$$
\begin{aligned}
& R_{\text {energy } y}=\sum_{k=1}^{K} L_{k} * t_{k} * \text { Hnorm } * \lambda \\
& G_{M I N K} \leq L_{k} \leq A_{k}{ }^{*} I_{C} / I O O \\
& I C=\sum_{i=1}^{N} G i-A U X
\end{aligned}
$$

Equation (2) shows revenue through energy charges, based on generation schedule given by RLDC, normative heat rate set by CERC and fuel cost. Equation (2.1) ensures that the schedule given by RLDC lies between the declared generation availability in MW and station technical minimum generation $\mathrm{G}_{\mathrm{MNNK}}$ (to maintain unit stability, below the technical minimum coal stations have to take oil support and gas turbine stations will face temperature constraints)

Where, $\mathrm{R}_{\text {energy }}$ : yearly revenue from energy charges in Rs.,

$\mathrm{L}_{\mathrm{k}}$ : Load schedule at time interval ' $\mathrm{k}$ '- (Stochastic Variable) i.e. scheduled generation by Regional Load Dispatch Center (ISO in India) in MW, $\mathrm{t}_{\mathrm{k}}$ : length of $\mathrm{k}^{\text {th }}$ time block in hours,

$\mathrm{H}_{\text {norm: }}$ Normative heat rate in Kcals per KWh fixed by regulator for payment of energy charges, 
$\lambda$ : Fuel cost in Rupees per Million Calories (currently 1US $\$=46$ Rupees approximately),

$\mathrm{G}_{\mathrm{MINK}}$ : Technical minimum station generation in $\mathrm{MW}$ for $\mathrm{k}^{\text {th }}$ time interval,

IC: Installed net station capacity in MW after accounting for normative auxiliary consumption,

$\mathrm{G}_{\mathrm{i}}$ : Capacity of $\mathrm{i}^{\text {th }}$ unit in MW,

$\mathrm{N}$ : total number of generating units, and

AUX: Normative Station Auxiliary Power Consumption in MW at full station load, specified by Central Electricity Regulatory Commission (CERC).

The UI charges are payable depending upon what is deviated from the schedule and also subject to the grid conditions at that point of time. UI charges are levied for difference in its Actual and Scheduled Generation/drawl. UI is payable or receivable depending on over or under generation. Rate of UI linked to average frequency of 15 minutes time block. UI charges are levied for difference in its Actual and Scheduled Generation/drawl. UI will be worked out for each 15 minutes time block. Charges for UI are frequency linked and are payable/ recoverable depending on grid frequency if:

- A generator generates more than schedule-Gets UI

- A generator generates less than the schedule - Pays UI

- A beneficiary overdraws power - Pays UI

- A beneficiary under draws power-Gets UI

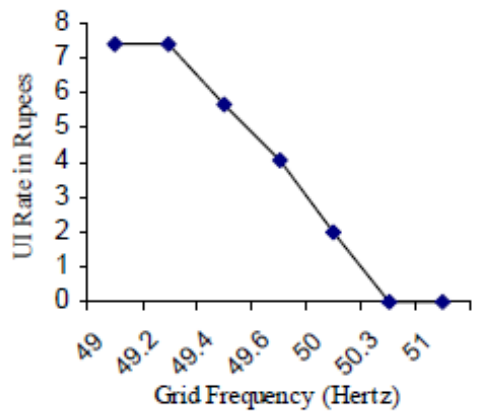

Figure 1 Unscheduled Interchange Rate (Rupees Per KWH)

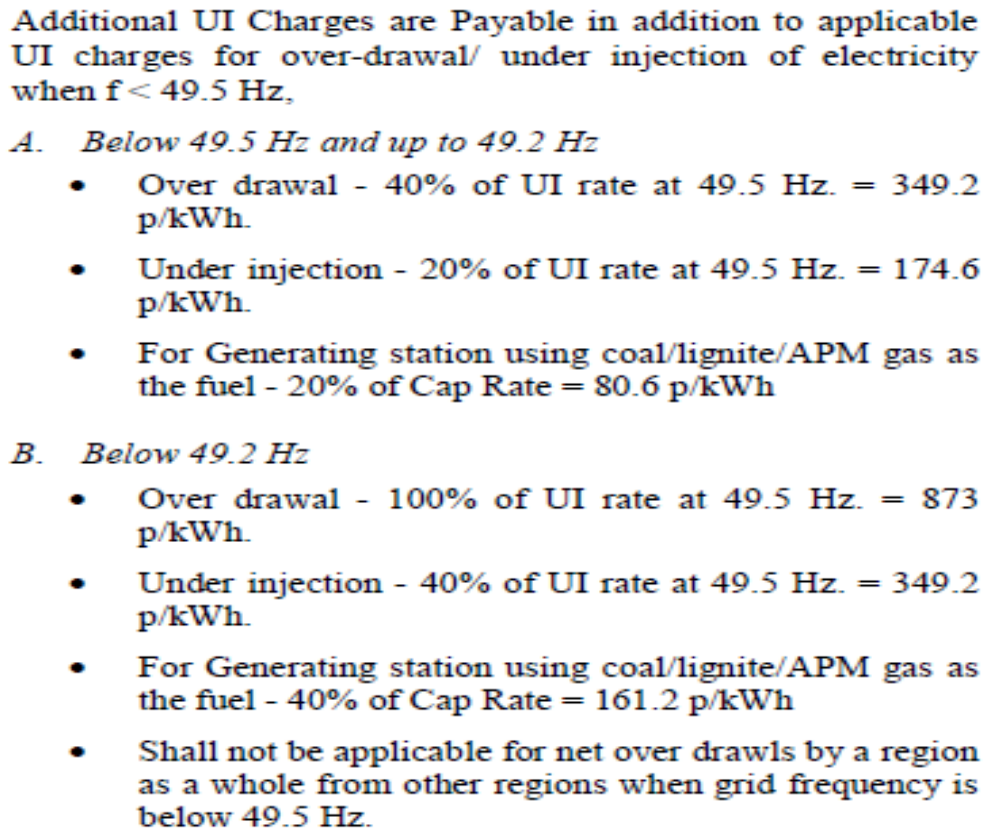

- Under injection - $20 \%$ of UI rate at $49.5 \mathrm{~Hz}$. $=174.6$ $\mathrm{p} / \mathrm{kWh}$.

- For Generating station using coal/lignite/APM gas as the fuel $-20 \%$ of Cap Rate $=80.6 \mathrm{p} / \mathrm{kWh}$

B. Below $49.2 \mathrm{~Hz}$

- Over drawal - $100 \%$ of UI rate at $49.5 \mathrm{~Hz}$. $=873$ $\mathrm{p} / \mathrm{kWh}$

- Under injection - $40 \%$ of UI rate at $49.5 \mathrm{~Hz} .=349.2$ $\mathrm{p} / \mathrm{kWh}$.

- For Generating station using coal/1ignite/APM gas as the fuel $-40 \%$ of Cap Rate $=161.2 \mathrm{p} / \mathrm{kWh}$

- Shall not be applicable for net over drawls by a region as a whole from other regions when grid frequency is below $49.5 \mathrm{~Hz}$

Under this system UI charges will be payable, if:

- a generator generates more than the schedule, thereby increasing the frequency;

a generator generates less than the schedule, thereby decreasing the frequency;

a beneficiary overdraws power, thereby decreasing the frequency;

a beneficiary under-draws power, thereby increasing the frequency. 


\section{The formulation of Penalty charges for not meeting the load obligation at any time interval for the entire time horizon is indicated by equation (3). A multiplication by 1000 is applied}

$$
\begin{aligned}
& \text { in (3) as the UI rate is in rupees per } \mathrm{KWH} \text {. The penalty at any } \\
& \text { time interval is the product of two random variables- } \\
& \text { unscheduled interchange (UI) and Energy Not served (ENS). } \\
& \text { Equations (3.1)-(3.3) convey the constraints associated with } \\
& \text { penalty estimation. } \\
& R_{\text {penaly }}=1000^{*} \sum_{k=1}^{K} E_{k} S_{k} * \mathrm{UI}_{\mathrm{k}} \\
& \text { ENS } S_{k}=\text { Maximum }\left\{0,\left(L_{k}-b_{k} * G_{M A X \pi}\right)\right\}^{*} t_{k} \\
& O \leq G_{\text {MAXz }} \leq I C
\end{aligned}
$$$$
\text { time interval is the product of two random variables- }
$$$$
\text { Equations (3.1)-(3.3) convey the constraints associated with }
$$

Where, R, penalty Yearly penalty charges due to unscheduled interchange on account of energy not served during $\mathrm{K}$ intervals,

$\mathrm{ENS}_{\mathrm{k}}$ : Energy not served at $\mathrm{k}^{\text {th }}$ time interval in $\mathrm{MWh}$,

UIk : Unscheduled Interchange (UI) rate in rupees/KWh - a stochastic variable,

$\mathrm{B}_{\mathrm{k}}$ : Station capacity degradation factor for $\mathrm{k}^{\text {th }}$ time interval ( $b_{\mathrm{k}}$ equal to 1 in the first time interval), and

\begin{tabular}{|c|c|c|c|c|c|c|c|c|}
\hline \multicolumn{2}{|c|}{$\begin{array}{c}\text { AVERAGE } \\
\text { FREQUENCY OF } \\
\text { TIIII BLOCK } \\
\text { (HZ) }\end{array}$} & \multirow{2}{*}{$\begin{array}{l}\text { UI RATE } \\
\text { W.E.F } \\
\text { 01.05.2010 } \\
\text { (PAISA. } / \\
\text { KWWH) }\end{array}$} & \multicolumn{2}{|c|}{$\begin{array}{c}\text { AVERAGE } \\
\text { FREQUENCY OF } \\
\text { TILIE BLOCK } \\
\text { (HZ) }\end{array}$} & \multirow{2}{*}{$\begin{array}{l}\text { UI RATE } \\
\text { W.F.F } \\
\text { 01.05.2010 } \\
\text { (PAISA / } \\
\text { KWWH) }\end{array}$} & \multicolumn{2}{|c|}{$\begin{array}{c}\text { AVERAGE } \\
\text { FREQUENCY OF } \\
\text { IIIIE BLOCK (HZ) }\end{array}$} & \multirow{2}{*}{$\begin{array}{l}\text { UI RATE } \\
\text { W.EF } \\
01.05 .2010 \\
\text { (PAISA } / \\
\text { KWWH) }\end{array}$} \\
\hline BEIOW & $\begin{array}{c}\text { NOT } \\
\text { BELOW }\end{array}$ & & BEL OW & $\begin{array}{c}\text { NOT } \\
\text { BELOW }\end{array}$ & & BELOW & $\begin{array}{c}\text { NOT } \\
\text { BELOW }\end{array}$ & \\
\hline & 50.20 & 0.00 & 49.94 & 49.92 & 217.00 & 49.66 & 49.64 & 497.00 \\
\hline 50.20 & 50.18 & 15.50 & 49.92 & 49.90 & 232.50 & 49.64 & 49.62 & 544.00 \\
\hline 50.18 & 50.16 & 31.00 & 49.90 & 49.88 & 248.00 & 49.62 & 49.60 & $\$ 91.00$ \\
\hline 50.16 & 50.14 & 46.50 & 49.88 & 49.86 & 263.50 & 49.60 & 49.58 & 638.00 \\
\hline 50.14 & 50.12 & 62.00 & 49.86 & 49.84 & 279.00 & 49.58 & 49.56 & 685.00 \\
\hline 50.12 & 50.10 & 77.50 & 49.84 & 49.82 & 294.50 & 49.56 & 49.54 & 732.00 \\
\hline 50.10 & 50.08 & 93.00 & 49.82 & 49.80 & 310.00 & 49.54 & 49.52 & 779.00 \\
\hline 50.08 & 50.06 & 108.50 & 49.80 & 49.78 & 325.50 & 49.52 & 49.50 & 826.00 \\
\hline 50.06 & 50.04 & 124.00 & 49.78 & 49.76 & 341.00 & 49.50 & & 873.00 \\
\hline 50.04 & 50.02 & 139.50 & 49.76 & 49.74 & 356.50 & \multirow{5}{*}{\multicolumn{3}{|c|}{$\begin{array}{c}\text { Each } 0.02 \mathrm{~Hz} \text { step is ecruivalent to } \\
15.5 \mathrm{p} / \mathrm{Kwh} \text { in the } 50.249 .7 \mathrm{~Hz} \\
\text { freq. range and } 47 \mathrm{p} / \mathrm{Kwh} \text { in } 49.7 \text { - } \\
49.5 \mathrm{~Hz} \text { freq. mange } \\
\text { (Applicable w.e. } 03.05 .2010 \text { ) }\end{array}$}} \\
\hline 50.02 & 50.00 & 155.00 & 49.74 & 49.72 & 372.00 & & & \\
\hline 50.00 & 49.98 & 170.50 & 49.72 & 49.70 & 387.50 & & & \\
\hline 49.98 & 49.96 & 186.00 & 49.70 & 49.68 & 403.00 & & & \\
\hline 49.96 & 49.94 & 201.50 & 49.68 & 49.66 & 450.00 & & & \\
\hline
\end{tabular}
$\mathrm{G}_{\mathrm{MAX}-\mathrm{K}}$ : Maximum station availability in MW at time block $\mathrm{k}$-Stochastic variable.

Under the frequency linked UI regime, charges will be paid to or levied on the generator for any deviations from schedules. These could be favourable if the generator is under-generating at high frequency or over generating at low frequency and unfavourable if the generator is over-generating at high frequency or under generating at low frequency conditions

Figure 2: Typical Average Frequency \& UI Rates

In a deficit scenario, where all the generators would have been fully despatched up to their declaration, the generators would utilise the design margins of the machine to achieve generation higher than their installed capacity (when the full capacity has been declared in the first instance) and thus would be able to inject more than their installed capacity into the system at time of low frequency conditions. This mechanism provides for the right price signals to the generators to generate more when the frequency is low and vice versa and also preempts the possibility of unwanted generation at higher frequency because the variable cost payment is now linked to scheduled generation and not actual generation. 


\section{TIME OF-USE TARIFF}

Comprises prices set in advance that vary among a small number of time periods (typically three) during the day and are presented as a customer tariff; the prices usually have a significant (30 to 40\%) differential between peak, off-peak and shoulder periods. ToU tariffs are offered or imposed on customers primarily by the electricity industry to improve the operation of electricity systems, but are also often promoted by pricing regulators with the objective of increasing economic efficiency. The time-varying pricing implications for emissions reduction can differ significantly between countries depending on the type of electricity generation system in place. Essentially the electricity generation system comprises base-load plants that operate almost continuously and are the source of most of the country's electrical energy, and the loadfollowing plants (intermediate and peaking plants) that are used to respond to shorter-term fluctuations in demand. Time-varying pricing could be seen as a mechanism for sharing some of the price risks between the electricity retailer and the customer. Higher income households are better able to respond to the price differentials for a positive financial outcome because they have access to and can afford efficient and programmable appliances. Disadvantaged households spend a proportionately higher percentage of their income on energy costs (despite using less energy overall than other households) and so are more exposed to the negative impacts of time-varying pricing. Today, a number of countries such as Canada, Australia, Italy, Netherlands and Japan offer smart metering and time varying tariff pricing. A number of incumbent utilities are considering new necessary product and service options (i.e. TOU contracts, RTP contracts, curtail-able service menus, price risk protection, economic development rates, fixed bill rate options, two-part tariffs and crossproduct bundling).Utilities have experimented with time differentiated pricing models for some time now. Hardware availability for real-time electricity monitoring was considered as a challenge in early implementation. Despite this fact, both consumer and utility experience with dynamic pricing was considered to be positive early on. Today, a number of smart metering solutions are available in market today enabling dynamic tariff schemes to be implemented. Equilibrium models based on mixed complementarily to estimate ex ante TOU prices. A multi-agent simulation approach has been considered to understand response of different customers to TOU pricing. Consumers, Retailer, Network Operator and Producer are considered as the stakeholders of the market.

\section{Modelling \& Simulating Tou Electricity}

This example demonstrates fitting a non-linear regression tree model to hourly day-ahead electricity prices in the New England pool region. The log electricity prices are modelled with two additive components: a deterministic and stochastic component. The deterministic component takes into account observed electricity price changes due to changes in fuel (natural gas) prices, the daily temperature, the hour of the day, day of the week and holidays. This is modelled using a regression tree. The stochastic component is modelled as a seasonal AR process with heavy tailed innovations.

\section{Import Data}

Data is loaded from a previously created MAT-file. The series consist of a vector of serial dates and the corresponding historical recorded temperature.

clear

load Data\ElecSeries

whos

$\begin{array}{lccc}\text { Name } & \text { Size } & \text { Bytes Class } & \text { Attributes } \\ \text { Date } & 52608 \times 1 & 420864 & \text { double } \\ \text { ElecPrice } & 52608 \times 1 & 420864 & \text { double } \\ \text { Hour } & 52608 \times 1 & 420864 & \text { double } \\ \text { NGPrice } & 52608 \times 1 & 420864 & \text { double } \\ \text { Temperatur } & 52608 \times 1 & 420864 & \text { double }\end{array}$

Also import a list of local holidays that span the dataset. These are read from an Excel spread-sheet. One can also use Financial Toolbox functions like HOLIDAYS, ISBUSDAY etc. to automatically generate holidays within the time range.

[numData, holidays] = xlsread ('Data\Holidays.xls');

holidays $=$ holidays $(2:$ end, 1$)$;

disp('Sample Holidays')

disp(holidays(1:20))

Sample Holidays

' $1 / 1 / 2004$ '

'1/19/2004' 
'2/16/2004'

'5/31/2004'

'7/5/2004'

'9/6/2004'

'11/25/2004'

'11/26/2004'

'12/24/2004'

'12/31/2004'

' $1 / 17 / 2005^{\prime}$

'2/21/2005'

'5/30/2005'

'7/4/2005'

' $9 / 5 / 2005$ '

' $11 / 24 / 2005$ '

' $11 / 25 / 2005^{\prime}$

'12/26/2005'

' $1 / 2 / 2006$ '

$' 1 / 16 / 2006$ '

\section{Plot Prices}

Create a visualization of the electricity prices from a macro and micro perspective $\operatorname{subplot}(2,1,1)$;

plot(Date, ElecPrice); dynamicDateTicks;

ylabel('\$/MWh'); title('Electricity Prices');

subplot (2,1,2);

dateind $=$ Date $>$ datenum('July 2, 2006') \& Date < datenum('Aug 13, 2006');

plot(Date(dateind), ElecPrice(dateind)); dynamicDateTicks;

ylabel('\$/MWh'); title('Electricity Prices from July 2, 2006 to Aug 13, 2006');
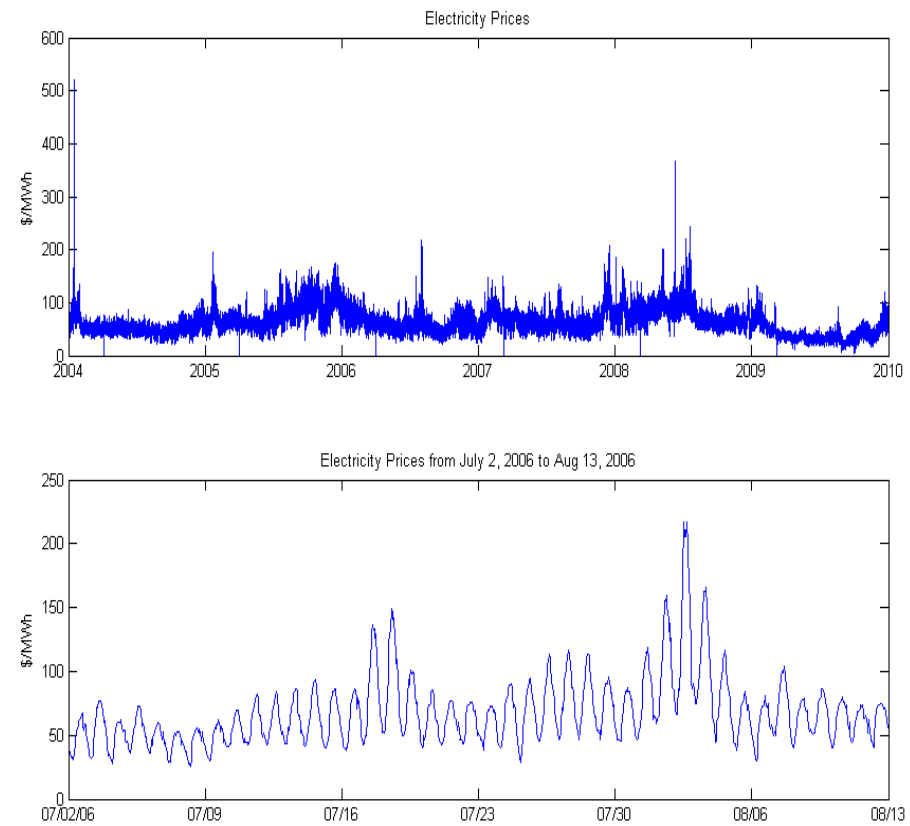

Figure 3

\section{Compute \& Visualize Model Performance}

Predict electricity prices using the model and compare them with the observed prices. The visualization function here is the same function used in the comparison of predicted and actual values for the Temperature model. The mean absolute error (MAE) is also displayed.

pred $=\operatorname{model}(X)$;

res $=$ logPrice - pred; 
fitPlot(Date, [logPrice pred], res);

disp(['Mean Absolute Error (in original units, not log units): \$' num $2 \operatorname{str}($ mean $(\operatorname{abs}(\exp ($ res $))))])$;

disp(['Mean Absolute Percent Error (in original units): ' num2str(mean(abs(exp(res)./ElecPrice*100))) '\%']);

Mean Absolute Error (in original units, not log units): \$1.0013

Mean Absolute Percent Error (in original units): $1.8097 \%$
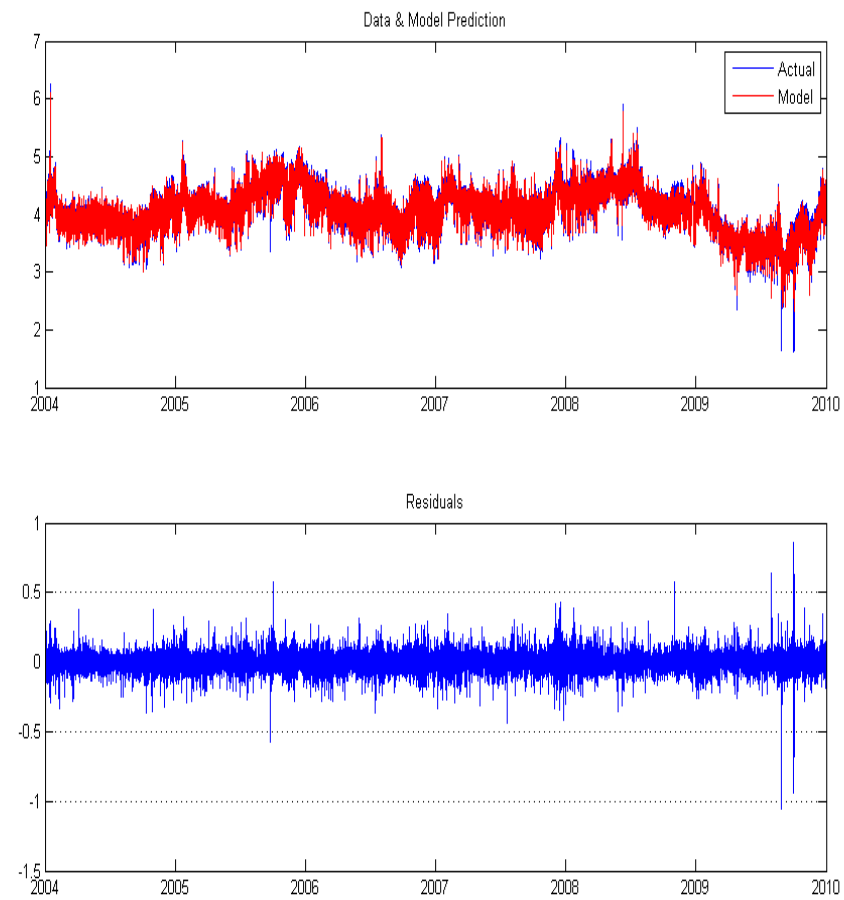

\section{Simulated model}

Figure 4

We can now simulate this model for 2009 and compare the simulated values to the observed data for 2009. Note that this is only simulating the electricity prices. The temperature and natural gas are constant. Therefore the large scale shape of the prices which is mostly determined by the deterministic component stays constant with smaller local variations with each trial.

ind $x=$ length(Date)-365*24+1:length(Date);

newDates = Date $($ ind $x)$;

simElec $=$ simulateElecPrices(elecModel, newDates, $1, X($ ind $x, 1), X($ ind $x, 2), X($ ind $x, 6)$, holidays $)$;

$\%$ Plot simulation results

axl = subplot $(2,1,1)$;

plot(newDates, ElecPrice(end-365*24+1:end))

title('Actual Electricity Prices');

ax2 = subplot $(2,1,2)$;

plot(newDates, simElec);

title('Simulated Electricity Prices');

linkaxes([axl ax2], 'x');

dynamicDateTicks([ax1 ax2], 'linked'); 

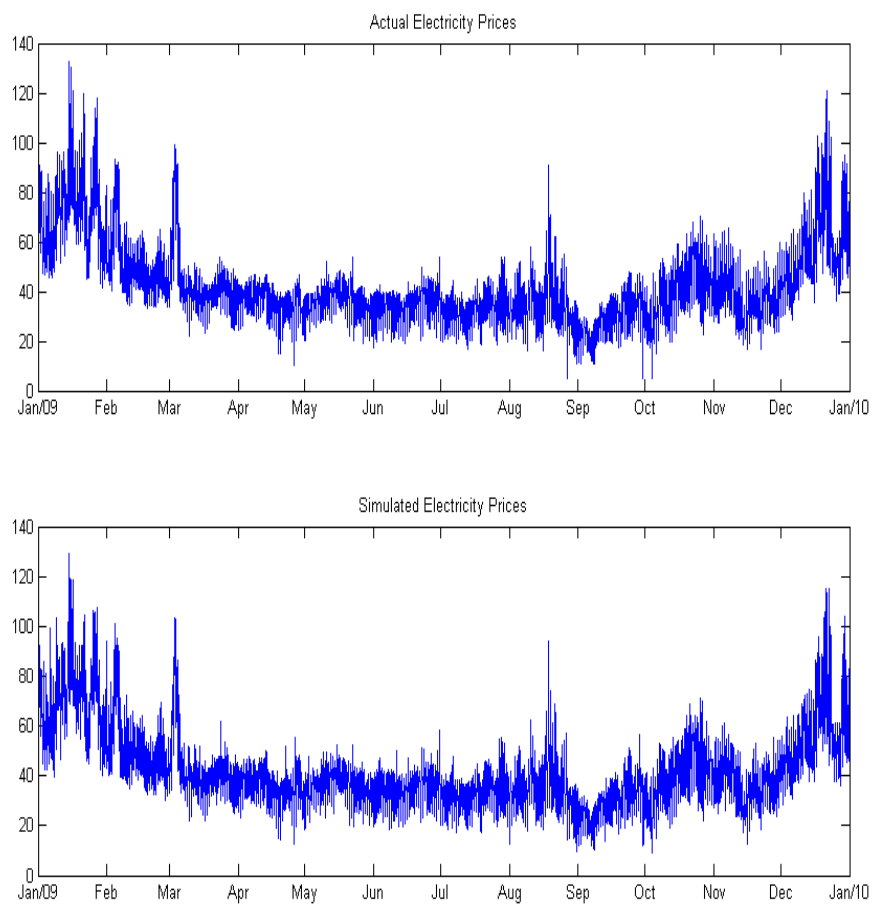

Figure 5

\section{FEED-IN TARIFF}

A feed-in tariff (FIT) is an energy-supply policy focused on supporting the development of new renewable power generation. FIT policies may require utilities to purchase either electricity, or both electricity and the renewable energy (RE) attributes from eligible renewable energy generators.

The FIT contract provides a guarantee of payments in dollars per kilowatt hour $(\$ / \mathrm{kWh})$ for the full output of the system 2 for a guaranteed period of time (typically 15-20 years). A separate meter is required to track the actual total system output. This payment guarantee is often coupled with the assurance of access to the grid, and the actual payment amount is usually differentiated based on technology type, project size, quality of the resource and/or other project-specific variables.

There are two main methodologies for setting the overall return that RE developers receive through FIT policies. The first is to base the FIT payments on the levelized cost of RE generation; the second is to base the FIT payments on the value of that generation to the utility and/or society.

In the first approach, the payment level is based on the levelized cost of RE generation, plus a stipulated return (set by the policy makers, regulators, or program administrators). The advantage of this approach is that the FIT payments can be specifically designed to ensure that project investors obtain a reasonable rate of return, while creating conditions more conducive to market growth.

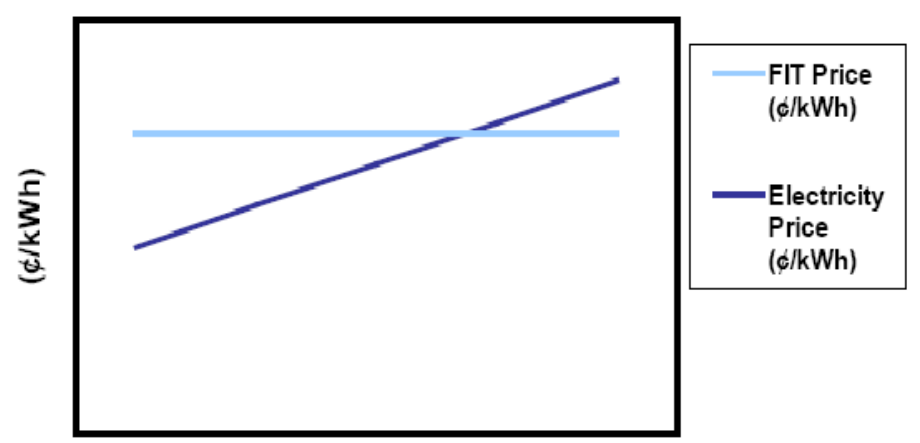

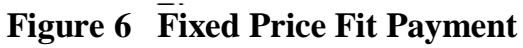


The second method of setting FIT payments is by estimating the value of the renewable energy. This value can be defined in a number of ways, either according to the utility's avoided costs, or by attempting to internalize the "externality" costs of conventional generation. This can be considered the "value-based" approach, which contrasts with the first, "RE project cost-based" approach.

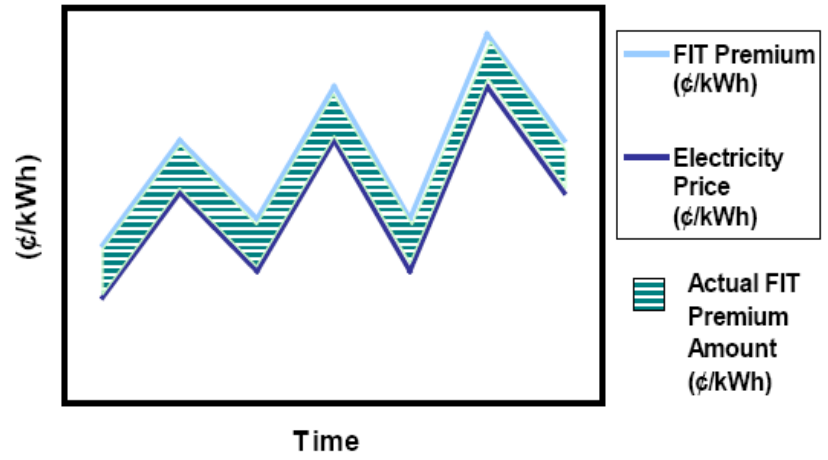

Figure 7 Premium-Level Fit Payment

There exist a number of FiT policy challenges. The first is the up-front administrative requirement: Detailed analysis is required to properly set the payment level at the outset. The payment level must ensure revenues will be adequate to cover project costs. If the FiT payments are set too low, then little new RE development will result. And if set too high, the FIT may provide unwarranted profits to developers. To achieve the right balance across a wide range of technologies and project sizes, many levels of differentiation are used. The FIT policy needs periodic revision to reflect evolving costs and market conditions.

Second, in contrast to other financial incentives for renewable, FITs do not decrease a developer's upfront costs. Policy makers enact investment tax credits, grants, and rebates to reduce the high, up-front capital costs of RE installations.

Another concern is the total cost of the program if it is designed to include tariffs for costlier emerging technologies. While FITs can be efficient at promoting these technologies, a decision must be made regarding the total acceptable cost burden, and how that impact is weighed related to the job creation and economic benefits that result.

Finally, frequent updates to the FIT program structure can lead to policy uncertainty. The more uncertain the policy structure - even a few years out - the riskier the RE investment is to the project financier.

\section{DYNAMIC PRICING}

Dynamic pricing is defined as any electricity tariff that recognizes the inherent uncertainty of real time supply costs.Different dynamic or time-variant tariff schemes that can be implemented in a smart meter include the following:

\section{- $\quad$ Real time pricing (RTP):}

Prices vary continuously (e.g. hourly), related to prices on the wholesale market. Prices are typically fixed one day in advance. RTP reflects marginal production costs even better, and lower prices can be provided during calm periods.

\section{Critical peak pricing (CPP):}

Several timeslots on a day or in a year - where consumption is very high - become significantly more expensive. It is often combined with flat rate or ToU pricing. Such CPP-slots can vary and customers are informed late, but can save much by avoiding these slots.

All tariff schemes puts requirements on smart meters. For CPP, even sub daily data needs to be downloaded to the meters. One of the major advantages of smart meters is that they can receive the different price information, and use this information to implement demand response in residential applications. Often demand response is implemented via load shifting, i.e. moving electricity usage in time. If smart meters need to enable automatic demand response, a data connection from the smart meters to the manageable loads (appliances) is necessary e.g. via a home automation system. In order to explore the possibilities of demand response via smart meters, we have analysed different scenarios under different tariff schemes. The simulation results are based on the synthetic load profiles for the different seasons (spring, summer, fall, winter) and days (weekday, weekend).As can be seen in the figure, residential users consume more in winter than in summer (heating, lighting) and the evening peak is slightly earlier. 


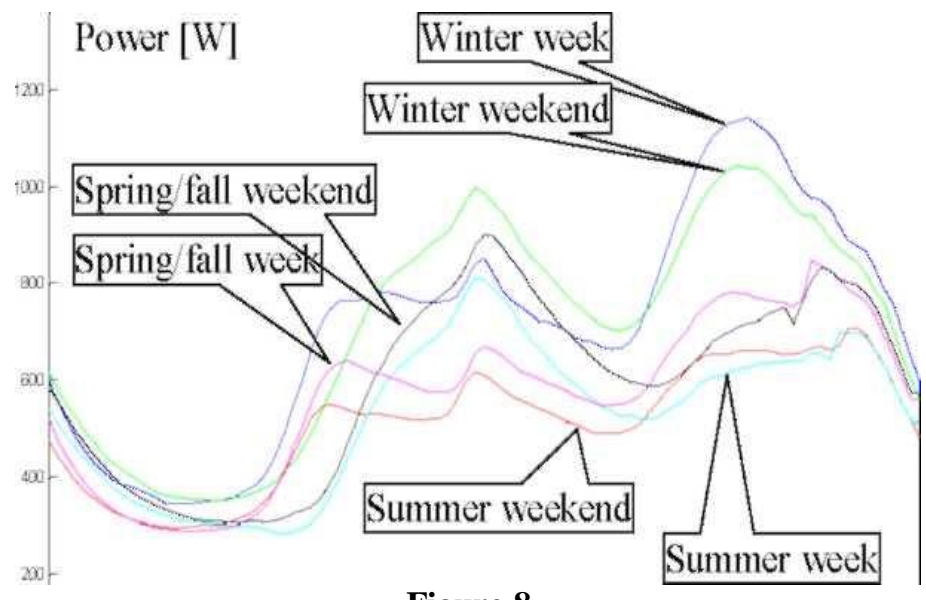

Figure 8

Average electricity consumption for a residential customer during different seasons, totalling 5000 $\mathrm{kWh}$ it was consumed (today called distributed generation) and install large conductors to handle the growing demand for electricity, but this solution proved to be costly (especially for rural areas which could not afford to build a local station or to pay for massive amounts of very thick copper wire), impractical (including, but not limited to, inefficient voltage conversion) and unmanageable.

If demand response is used to react to price incentives, this will reduce overall costs for the energy generation, as less (expensive) peak generators need to be run and more (cheaper) base load can be generated. Using demand response however does not automatically reduce the overall electrical energy consumption; often there is a small energy increase (several \%). In order to make a cost optimisation, the following hypotheses have been taken. The price per kWh for electricity is calculated based on an average among major suppliers on the Flemish market in October 2007, both for a flat tariff (at $17.85 \mathrm{Ect} / \mathrm{kWh}$ ) and a double tariff with two time zones:

- weekdays-daytime (at $19.25 € \mathrm{ct} / \mathrm{kWh}$ )

- weekdays-nighttime + weekend (at $11.98 € \mathrm{ct} / \mathrm{kWh})$.

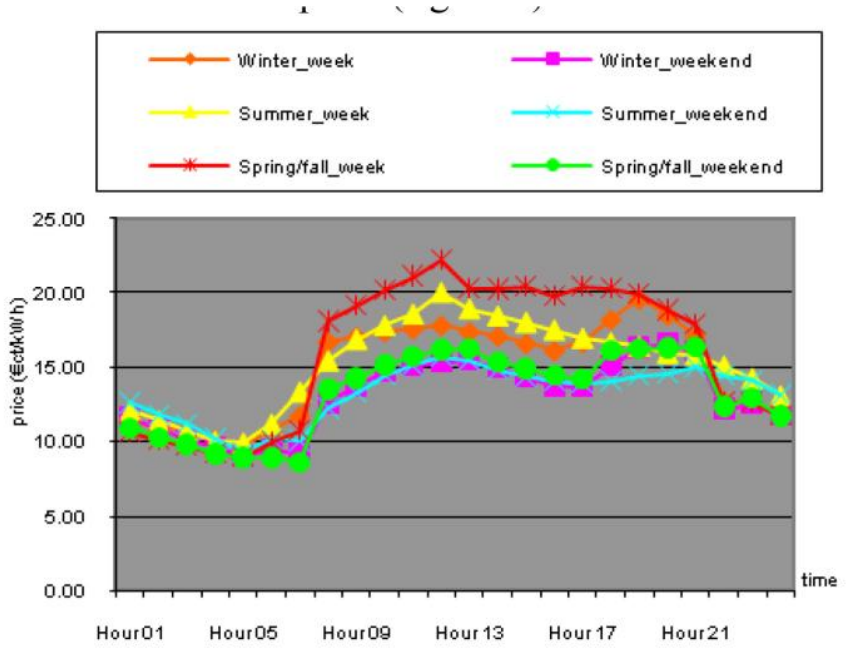

Figure 9 A Reference Scenario - Variation Of Price With The Hours

VII. Critical Peak Pricing Tariff

Critical Peak Pricing (CPP) refers to a method of pricing electricity whereby "Time of Use (TOU) Pricing" is in effect with the exception of certain "peak periods" at which time electric prices may reflect the costs of generating and/or purchasing electricity at the wholesale level. It aims to reduce load during the relatively few, very expensive hours more dynamically. In CPP tariff design, the important elements are the time window over the peak price period and the degree of price differentiations between the peak and off peak times.

CPP has been applied by a number of energy companies together with the time-of-use pricing (TOU pricing), real-time pricing (RTP) and peak-time rebate (PTR). Since the main purpose of setting time-based pricing is to encourage customers to shift load during high-price hours, CPP are usually assessed for certain hours on event days (often limited to 10-15 per year). Compared with RTP, which allows electricity prices change per half hour (exceptionally more often), CPP could provide a less complex tariff for customers because 
the period of charging at a specified price is far longer. This rate refers only to large-load consumers who enter into pre-established peak load reduction agreements. Residential customers could hardly provide their responses to price variation. Since the primary purpose of setting the tariff is to keep the balance between the cost of electricity suppliers and the revenue from retail market together with realizing the load shifting during critical peak hours, CPP which is set based on TOU and RTP augments a time-invariant or TOU rate structure with a flexible pre-set high price during periods of system stress.

Typically, CPP rate, peak rate and off peak rate are set in a CPP tariff design. Price differentiations between them could help to achieve the goal of promoting demand response and shifting energy from critical peak hours to other hours. Critical peak and Peak pricing window together with the value of each rate are the dominative factors in the proposed tariff design. The application of CPP tariff which is set based TOU and RTP is expected to keep the balance between the cost of electricity suppliers and the revenue from retail market. At the same time, it should have the ability to encourage customers to shift load in response to the rate design. The statistical results of market index data are considered as the basis in the process of determining time windows and rates in on-peak and off-peak hours.

CPP whereby time-of-use prices are in effect except for certain peak days, when prices may reflect the costs of generating and/or purchasing electricity at the whole-sale level. It usually offers a year-round rate to customers to overcome the supply shortage in critical peak days or hours.

COMPARISON BETWEEN TOU AND CPP

\begin{tabular}{|c|l|c|c|c|c|}
\hline \multicolumn{2}{|c|}{} & off-peak & mid-peak & on-peak & critical-peak \\
\hline \multicolumn{2}{|c|}{ TOU } & $p_{\text {off }}$ & $p_{\text {mid }}$ & $p_{\text {on }}$ & - \\
\hline \multirow{2}{*}{ CPP } & $\begin{array}{l}\text { non-critical } \\
\text { days }\end{array}$ & $p_{\text {off }}$ & $r p_{\text {mid }}$ & $r p_{\text {on }}$ & - \\
\cline { 2 - 6 } & critical days & $p_{\text {off }}$ & $p_{\text {mid }}$ & $p_{\text {on }}$ & $p_{\text {critical }}$ \\
\hline
\end{tabular}

\section{SMART METERING}

Advanced metering can be implemented with different levels of intelligence associated to the meter.Smart meters can easily implement different tariff schemes for electrical energy. Tariff schemes can be time-invariant (flat rate, declining block rate, inverted block rate) or time-variant (time-of-use pricing (ToU), critical peak pricing (CPP), real-time pricing (RTP).

Via the tariff schemes, smart meters can play an important role in changing the consumption pattern of residential users if they are combined with load shifting. As such they can improve energy efficiency by attaining a better load profile at aggregated level. Typically three types can be distinguished, in order of increasing interaction level and feature contents:

- AMR: Automated Meter Reading implies remote reading of measurement registers of an electricity meter without physical access to the meter. It can be implemented via a temporary radio link from a car passing by in the street while interrogating the meters, or as a communication link (always connected to the meter) from the data connected devices. Such link may use wireless or wired-communication media.

- AMM: Automatic Meter Management extends AMRs with the ability to manage to manage meters remotely. For instance, it allows for the disconnection of the customers for dimming their usage or for re-connection of the customers.

- Smart Metering extends AMM with control abilities. For instance, it allows for shutting down of several customers simultaneously on short notice, to balance the grid in case of an incident or for demand response, for usage flattening or for load shifting, or for integration in home automation systems -for automatic response to varying electricity prices-, etc. As such, smart meters are an indispensable enabler in a context of smart grids which deploy advanced information and communication technology to control the electrical grid.

\section{CONCLUSIONS}

The Availability Based Tariff has dramatically streamlined the operation of regional grids in India. Firstly, through the system and procedure in place, constituents' schedules get determined as per their shares in Central stations, and they clearly know the implications of deviating from these schedules. Any constituent which helps others by under-drawl from the regional grid in a deficit situation gets compensated at a good price for the quantum of energy under-drawn. Secondly, the grid parameters, i.e., frequency and voltage, have improved, and equipment damage correspondingly reduced. During peak load hours, the frequency can be improved only by reducing drawls, and necessary incentives are provided in the mechanism for the same. High frequency situation on the other hand, is being checked by encouraging reduction in generation during off-peak 
hours. Thirdly, because of clear separation between fixed and variable charges, generation according to meritorder is encouraged and pithead stations do not have to back down normally. The overall generation cost accordingly comes down. Fourthly, a mechanism is established for harnessing captive and co-generation and for bilateral trading between the constituents. Lastly, the Availability Tariff, by rewarding plant availability, enables more consumer load to be catered at any point of time.

Time-of-use tariffs which do not incentivize a reduction in energy consumption do however encourage electricity consumption at off-peak times. Where possible, consumers on a TOU tariff should shift consumption from peak to off-peak periods. It was shown that this can lead to significant cost savings. While the practicality of this change in consumption is not always possible, a reduction in energy use through energy efficiency programs will also lead to significant cost saving.

Critical Peak Pricing (CPP) refers to a method of pricing electricity whereby Time-of-Use (TOU) Pricing is in effect with the exception of certain peak periods at which time electric prices may reflect the costs of generating and/or purchasing electricity at the wholesale level. It aims to reduce load during the relatively few, very expensive hours more dynamically. In CPP tariff design, the important elements are the time window over the peak price period and the degree of price differentiations between the peak and off peak times. In case Real Time Pricing is implemented, a daily update of tariffs is given. For CPP, even sub daily data is given the meters. In order to allow customer to participate conveniently, CPP contracts are sign up based on ToU contracts, and CPP rate structures include the tariffs of critical days and non-critical days. The application of CPP tariff which is set based TOU and RTP keeps the balance between the cost of electricity suppliers and the revenue from retail market. It also encourages customers to shift load in response to the rate design. The statistical results of market index data are considered as the basis in the process of determining time windows and rates in on-peak and off-peak hours.

All tariff schemes puts requirements on smart meters. Smart meters receive the different price information, and use this information to implement demand response in residential applications. Demand response is implemented via load shifting. Smart meters enable automatic demand response to manage the loads. Smart metering considers the minimum electricity cost scheduling problem of smart home appliances so the operation characteristics, such as expected duration and peak power consumption of the smart appliances are adjusted through a power profile signal.

\section{REFERENCES}

[1] Risk Constrained Operation Planning Model for a Genco in Availability Based Tariff Regime in India; N.Vaitheeswaran, and R. Balasubramanian, Senior Member, IEEE

[2] Principles of Modern Electricity Pricing; Mohan M. Wasinghe, Senior Member, IEEE

[3] Electricity Tariff Structure Review: Alternative Tariff Structures - A Consultation Paper; Commission for Energy Regulation (CER)

[4] Electricity in India; An International Energy Agency Paper

[5] Tariff Setting in the Electric Power Sector: Base paper on Indian Case Study; Sanjeev S. Ahluwalia, Secretary, Central Electricity Regulatory Commission \& Gaurav Bhatiani, Area Convener Energy Reforms Group, TERI

[6] Towards Sustainable Energy Tariffs: A Report to the National Consumer Council by the Centre for Sustainable Energy; by William Baker and Vicki White

[7] A Model for Efficient Consumer Pricing Schemes in Electricity Markets: Transactions on Power Systems, E Celebi and JD Fuller, IEEE

[8] Smart Metering Tariff Schemes Combined With Distributed Energy Resources; G. Deconinck and B. Decroix, In International Conference on Critical Infrastructures

[9] The Role of Advanced Metering and Load Control in Supporting Electricity Networks: International Energy Agency Demand Side Management Programme; Rese D.J. Crossley, Energy Futures Australia Pvt. Ltd.

[10] Scheduling Smart Home Appliances Using Mixed Integer Linear ; Cheong Sou, James Weimer, Henrik Sandberg, and Karl Henrik Johansson, 2011 50th IEEE Conference on Decision and Control and European Control Conference

[11] Smart Metering Tariff Schemes Combined with Distributed Energy Resources; G. Deconinck, B. Decroix K.U.Leuven, ESAT/ELECTA (Belgium)

[12] Critical Peak Pricing Tariff Design for Mass Consumers; Zhimin Wang, and Furong Li, Senior Member, IEEE

[13] Optimal Implementation Strategies for Critical Peak Pricing; Qin Zhang, Student Member, IEEE \& Xifan Wang, Fellow, IEEE and $\mathrm{Min} \mathrm{Fu}$

[14] Potential Problems with Large Scale Differential Pricing Programs; Jason W. Black, IEEE Member and Rajesh Tyagi 